\title{
Development of Models for Managing Network Congestion on Global System for Mobile Communication (GSM) in Nigeria
}

\author{
Kuboye B. M. ${ }^{1, *}$, Alese B. K. ${ }^{1}$, Fajuyigbe O. ${ }^{1}$, Adewale O. S. ${ }^{2}$ \\ ${ }^{1}$ Department of Computer Science, Federal University of Technology, P. M. B. 704, Akure, Nigeria \\ ${ }^{2}$ Department of Computer Science, Joseph Ayo Babalola Univerisity, Ikeji-Arakeji, Osun State, Nigeria
}

\begin{abstract}
Unexpectedly, the level of patronage being experienced in Global System for Mobile Communication (GSM) in Nigeria is overwhelming. This is as a result of freedom of calling from anywhere at anytime and clarity of the voice enjoyed in GSM since it is on a digital technology platform. This has brought a lot of congestion in the network resulting in poor services by the operators. This research has developed a management algorithm for the management of the congestion experienced in the GSM network in Nigeria. It explores the use of Erlang-B in determining the appropriate probability level for some range of subscribers. Thereafter, when there is congestion, block time sharing, dynamic allocation without time slicing, dynamic allocation time slicing with signal sensing, frequently recent call allocation, and priority allocation algorithms were developed to manage the congestion. Furthermore, a hybrid algorithm was developed that integrates all the algorithms together in other to manage the congestion considering all the strengths and constraints of each algorithm. If the recommended congestion management algorithm is followed comprehensibly, the congestion problem on the GSM network will be reduced drastically.
\end{abstract}

Keywords Communication, GSM, Mobile, Model, Simulation

\section{Introduction}

The introduction of digital systems gave rise to the second generation $(2 \mathrm{G})$ of cellular telephones and it was at this point that Global System for Mobile Communications (GSM) was released. GSM is more advanced and handles more subscribers than analog systems (Kuboye and Alese, 2009). Global system for mobile communications (GSM) uses more advanced technology and handles more subscribers than the analog cellular network due to the use of Time Division Multiple Access to divide the channel in time (Kuboye, 2010). GSM is a major digital cellular radio network in Europe since 1980 s, where it is used in the $900 \mathrm{MHz}$ radio band frequency. GSM has been standardized to $900 \mathrm{MHz}$, $1800 \mathrm{MHz}$, and $1900 \mathrm{MHz}$. The $900 \mathrm{MHz}$ and $1800 \mathrm{MHz}$ used the same base band signals, but they operate on different carrier frequencies. The radio frequency separation between matching the uplink and downlink carrier for $900 \mathrm{MHz}$ is $45 \mathrm{MHz}$ while that of $1800 \mathrm{MHz}$ is $90 \mathrm{MHz}$. The $1900 \mathrm{MHz}$ is used mainly in North America.

The method of sharing the radio spectrum bandwidth of

* Corresponding author:

kubonline@yahoo.co.uk (Kuboye B. M.)

Published online at http://journal.sapub.org/jwnc

Copyright (C) 2011 Scientific \& Academic Publishing. All Rights Reserved
GSM is known as Time- and Frequency-Division Multiple Accesses (TDMA and FDMA). FDMA part involves the division by frequency of the maximum $25 \mathrm{MHZ}$ bandwidth into 124 carrier frequencies spaced $200 \mathrm{KHZ}$ apart (Harte et al, 1999). The actual number of carrier in GSM is 125 but due to interference to other systems, the very first carrier is not used thus reduced the carrier to 124. One or more carrier frequencies are allocated to each base station. Each of these carrier frequencies is then divided in time, using TDMA scheme into 8 timeslots as seeing in fig 2.0. Each of these timeslots is a physical channel occupied by an individual user (carries control and a traffic data in a burst form) (Mehrotra, 1997). Typical GSM handsets carrier channel, thus allows up to eight users to simultaneously share a single radio channel.

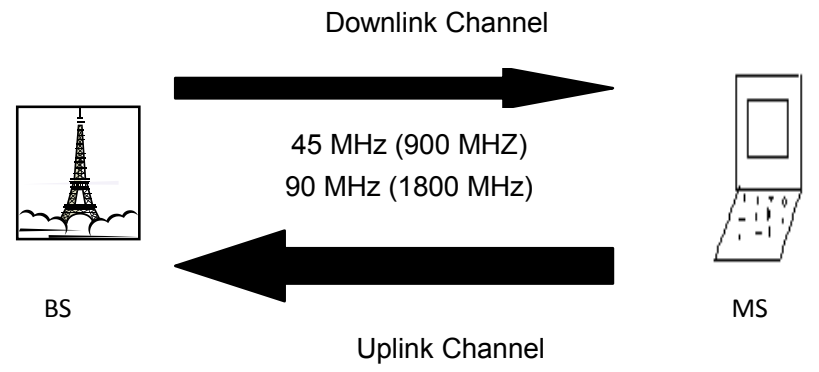

Figure 1. GSM Duplex Radio (Source: Mehrotra, 1997) 


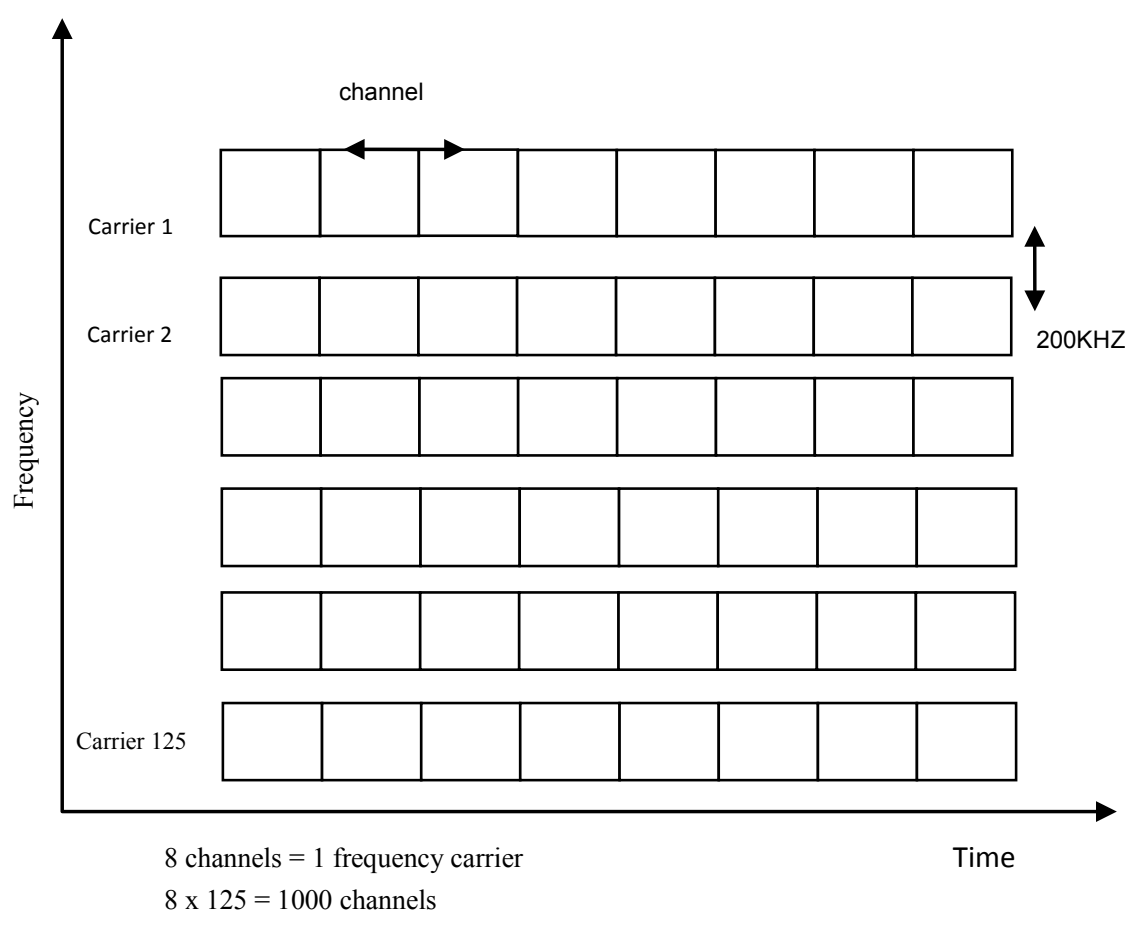

Figure 2. Time and Frequency -GSM Radio spectrum Division

The management of this radio frequency among subscribers remains a problem all over the world including Nigeria. A lot of literatures have been written in respect of this problem (Gupta and Sachan, 2007; Candan and Salamah, 2006). The congestion experienced today is a result of this problem at hand. This research took a critical look at the GSM network in Nigeria and come up with algorithms that can be adapted on the GSM network to minimize this congestion.

\section{Modeling Gsm Networks Effectiveness Using Erlang B Formula}

Traffic engineering is key to effective wireless telephony network design and planning. Traffic characteristics need to be addressed and once accomplished; mathematical models can be applied to dimension the network. Dimensioning determines the amount of traffic the radio channel can capture. An accurate traffic model for the system will greatly enhances the accuracy of network dimensioning, extending network investments and increasing the profit returns. When a network is properly dimensioned, the channels will be used more efficiently and will produce greater user satisfaction (Konstain et al 2003).

On the other side, poor modeling of traffic characteristics can actually affect system performance. When cells are under-dimensioned, not enough radio channels are installed. This will lead to congestion in the cell, and it also may affect overall system performance.

Traffic planning focus on the busy hour, which is for effective traffic management, the engineers must know the hour when the network normally experiences the heaviest traffic. The network planning is built around three variables:

- Servers: This is the channel that handles calls.

- Traffic: This is the use of radio channels.

- Grade of service: The probability that all servers will be busy when a call attempt is made.

Network dimensioning relied on Erlang B formula for its mathematical models. This formula was formulated by Agner k. Erlang while he was in Copenhagen Telephone Company in 1908 (Angus, 2001). Erlang B Formula is used to calculate the probability that a resource request from the customer will be denied due to lack of resources. When networks Engineer already know the blocking probability in advance, then he will be able to plan ahead the means of increasing the number of channels when the number of users to cause this blocking ratio is approaching (Boulmalf and Akhtar, 2003).

\subsection{Key Concepts in Erlang B Formula}

Traffic: This is defined as the use of given resources. In wireless telephoning networks, traffic is defined as the use of radio channels. When a user makes a phone call, a channel is seized for communication thereby generating traffic. Therefore, we can say that Traffic is proportional to the Average Call duration

BUSY HOUR: The load handled by a system varies a lot based on the time of day and days of the week. Most systems are heavily loaded for a few hours in a day. This is the period when incoming calls are most likely to be blocked or turned away, so this is the time statistics are calculated. The main objective of resource dimensioning is to make sure that the system performs well during these busy hours. This will 
make sure that system has adequate resources to handle peak as well as off peak hour.

BLOCKING PROBABILITY: The blocking or outage probability is defined as the probability that a call is blocked. It is a measure of Grade of service (Salim and Bli, 2008). In other words, this defines the chance that a customer will be denied service due to lack of resources. For example a blocking probability of 0.01 means that $1 \%$ of the customers will be denied service. Most of the time blocking probability is calculated during the peak (busy) hour.

GRADE OF SERVICE: The percentage of incoming calls turned away during the busy hour because all lines are busy at the time of the call. Grade of service is directly related to the blocking probability. A higher grade of service guarantee to the customer means ensuring low blocking probability during the busy hours.

NUMBER OF LINES (C): The number of independent phone lines or the number of customers that subscribe to the phone service. This determines the number of calls that can be serviced concurrently.

SERVICE TIME: The total time needed by a resource to handle one call.

WAIT TIME: The total time customers will have to wait in the queue before they get any service.

Arrival Rate ( $\lambda$ ): The arrival rate is Poisson distribution with parameter lambda $(\boldsymbol{\lambda})$. It is the number of calls that arrive per unit time. If five hundred calls arrive in an hour, on average, the Arrival rate is 500 calls/hour.

Service Rate $(\mu)$ : The mean number of calls serviced per unit time. If it takes 5 minutes to service one call, then 12 $(60 / 5)$ calls may be serviced in one hour and the service rate is 12 .

Total traffic in ERLANG (RHO $(\ell=\lambda / \mu)$ ): Erlang is a unit of traffic measurement. It is the ratio of Arrival Rate to Service Rate (lambda/mu). It is also referred to as busy hour traffic or offered traffic. It is the amount of time an average subscribers uses his phone during the so-called busy hour, i.e., the hour of the day when we expect the highest number of calls (Kleinrock, 1975).

For example, if in a wireless system, where 500 calls come in one hour and each call takes 20 minutes to service.

Total offered traffic $(\boldsymbol{\ell})=$ Arrival Rate/Service rate

$$
\ell=\lambda / \mu
$$

From the question, Arrival rate $(\lambda)=500$, Service Rate per hour is $(\mu)=60 / 20=3$, Substitute these parameters in equation 1

$$
\ell=500 / 3=166.67
$$

Alternatively you can use this formula

Total offered traffic

$$
(\ell)=(N * M) / 3600
$$

$\mathrm{N}=$ Number of calls per hour, and

$\mathrm{M}=$ Duration of each call per seconds

Applying this in Equation 2, then we have

$$
\begin{gathered}
\ell=500 *(20 * 60) / 3600 \\
\ell=(500 * 1200) / 3600=166.67
\end{gathered}
$$

Erlang B Formula is used to calculate the probability that a resource request from the customer will be denied due to lack of resources. It is the probability that all channels (n) are busy. It gives the proportion of time that no new calls can enter the system.

Erlang B formula is stated below:

$$
\mathrm{P}_{\mathrm{bl}}=\left(\ell^{n} / n !\right) /\left(\sum_{i=0}^{n} \ell^{i} / i !\right)
$$

Where $\ell=$ offered traffic in erlang, $\mathrm{n}=$ number of lines.

This Erlang-B formula is critical because it governs the relationship among blocking probability $\left(\mathrm{P}_{\mathrm{bl}}\right)$, offered traffic in Erlang $(\boldsymbol{\ell})$ and the number of traffic channels (n). Given any two of the values, the remaining variable can be determined (Cushine and Houstine, 1998).

\subsection{How to Use Erlang B Formula}

Collect traffic data: You need to know how much traffic will try to use the network each hour for five to ten business days.

Determine the average busy hour: Select the busiest hour each business day, total the traffic, then divide by the number of days.

Choose a target grade of service. P. 02 means there is a $2 \%$ probability of getting a busy signal. Choose the best one that suite your purpose. Have it in mind that P.01 is the best while P.10 is the worst.

Use the Erlang B: This calculates the number of channels you need to carry the amount of traffic with your target grade of service. Whatever your result is must be considered. What that means you need to consider if you can afford the number of channels that the result gives you or else you need to adjust the grade of service until you get the appropriate one you can afford.

\subsection{Loading Channel Using Erlang B Formula}

We are going to use three case studies using Erlang formula to determine the accepted loading for our model

Loading: This refers to the total number of subscribers a channel is expected to serve. A loading of 200 subscribers means, the channel is expected to service 200 subscribers. The loading was be studied with three loadings; 200, 250, 280.

(Angus, 2001)

\section{Simulating the Process}

\subsection{Simulation One}

Loading a finite number of subscribers of 200 per channel (8 timeslots) and we want each call to be served for maximum of 60 seconds. Applying Erlang traffic, we would be able to determine the probability of blocking.

$$
\begin{gathered}
\mathrm{P}_{\mathrm{bl}}=\left(\ell^{n} / n !\right) /\left(\sum_{i=0}^{n} \ell^{i} / i !\right) \\
\ell=n^{*} m / 3600
\end{gathered}
$$

and, 
If $\mathrm{n}=200, \mathrm{~m}=1$ minute $=60$ seconds, then

$$
\ell=200 * 1 * 60) / 3600=3.3
$$

Therefore,

$$
\mathrm{P}_{\mathrm{bl}}=\left(3.3^{8} / 8 !\right) /\left(\sum_{i=0}^{n} 3.3^{i} / i !\right)
$$

Expanding this will give,

$$
\begin{gathered}
=03488 / 26.5764=0.01 \\
P_{b l}=0.01
\end{gathered}
$$

\subsection{Simulation Two}

Loading a finite number of subscribers of 250 per channel ( 8 timeslots) and we want each call to be served for maximum of 60 seconds. Applying Erlang, we would be able to determine the probability of blocking;

$$
P_{b l}=\left(\ell^{n} / n !\right) /\left(\sum_{i=0}^{n} \ell^{i} / i !\right)
$$

And

$$
\ell=n^{*} m / 3600
$$

If $\mathrm{n}=250, \mathrm{~m}=60$ seconds, then

$$
\ell=250 * 1 * 60) / 3600=4.2
$$

Therefore,

$$
P_{b l}=\left(4.2^{8} / 8 !\right) /\left(\sum_{i=0}^{n} 4.2^{i} / i !\right)
$$

Expanding this will give,

$\mathrm{P}_{\text {blocking }}=0.04$ approximately.

\subsection{Simulation Three}

Loading a finite number of subscribers of 280 per channel (8 timeslots) and we want each call to be served for maximum of 60 seconds. Applying Erlang, we would be able to determine the probability of blocking;

$$
P_{b l}=\left(\ell^{n} / n !\right) /\left(\sum_{i=0}^{n} \ell^{i} / i !\right)
$$

and,

$$
\ell=n^{*} m / 3600
$$

If $\mathrm{n}=250, \mathrm{~m}=60$ seconds, then

$$
\ell=(280 * 1 * 60) / 3600=4.67
$$

Therefore,

$$
P_{b l}=\left(4.67^{8} / 8 !\right) /\left(\sum_{i=0}^{n} 4.67^{i} / i !\right)
$$

Expanding this will give,

$\mathrm{P}_{\mathrm{bl}}=0.06$ approximately.

\section{Comments on the Three Simulations}

The result of case study one indicates that $1 \%$ of the 200 subscribers will be denied access, $4 \%$ of 250 subscribers will be denied access and $6 \%$ of 280 subscribers will be denied access under the same condition of $60 \mathrm{~s}$ maximum time.

The Erlang B deals with the number of calls during the busiest hour, but here we are dealing with the following;

- Finite number of subscribers that are potential callers and not the highest number of subscribers that call during a particular hour Every call is given equal time sharing

- At any point in time, not more than $10 \%$ of the subscribers will be ready to call at any point in time.

- Out of those that are ready to call, not more than $40 \%$ will be ready to spend more than 1 minute considering the tariff of GSM services in Nigeria.

- We can see that congestion will be minimized with this type of model.

The operators should consider the cost of equipment, installation, maintenance, profit returns and the location of the base station when choosing any of the above loading case studies (Kuboye, 2006). Taking all factors into consideration, we suggest the case studies two for the operators. The reason for this choice is that, for every 250 calls, only ten calls will be denied as against the other situation. If we are to choose 200 calls case study, the cost of maintenance of the system will be too high and this might not allow the operator to break even. If we are to choose the third case study, there will be too many denials and this will not be healthy for the operators. So, with the second case study, there will be minimal congestion and a good profit returns for the operators. With these, there will be minimal congestion and a good profit returns.

It is almost impossible to prevent network congestion due to some unexpected events, such as accidents and adverse weather. These cases generate abnormally high traffic. When users experience congestion, they make the problem worse. Upon reaching a busy signal, most people try to make the call again, or even a few times, to get a channel. This can significantly congest the network. Also, it violates the assumption that customers (calls) blocked by the system wouldn't return to the network. The Erlang B formula, doesn't apply in this kind of situation.

\section{Models for Managing Congestion}

How do we now manage the congestion that will result from the loading model chosen or other unexpected sources? The following models will be considered:

i. Block time sharing

ii. Dynamic allocation without time slicing

iii. Dynamic allocation time slicing with signal sensing

iv. Frequently recent call allocation

v. Priority allocation

\subsection{Block Time Sharing}

Each call is given a specific block of time and until the time expires no other call can use the channel. Each call is given full access to the system according to the time allocated but as soon as the time expired, a control is passed to pre-empt the call so as to allow other call to have access to the channel. Advantages of this method are:

- It does not allow any call to a channel more than the allotted time.

- It also gives access to the call without interruption from 
any other call within the time limit.

- It allows equal sharing among the call

Its draw back is that it wastes service time. For those calls that do not finish their allotted time before they exit the channel, the remaining time will be wasted.

1. START

2. SET THE BLOCK TIME

3. DO WHILE SERVICE $=$ TRUE

4. SET $K=1 / /$ INITIALISING THE TIMESLOT

5. DO WHILE NOT FREE AND $\mathrm{K}<=8 / /$ TESTING FOR FREE TIMESLOT

6. $\mathrm{K}=\mathrm{K}+1$

7. LOOP

8. IF TIMESLOT $=$ FREE THEN

9. LOAD THE CALL TO TIMESLOT (TK )

10. WHILE SERVICE_TIME $<$ BLOCK_TIME OR SERVICE_TIME $<$ AIR_TIME

11. CONTINUE THE $\overline{\mathrm{C} A L L}$

12. WEND

13. ELSE

14. REJECT THE CALL

15. END IF

16. FETCH THE NEXT CALL

17. LOOP

\subsection{Dynamic Allocation without Time Slicing}

This will allow calls to occupy the channel without given any time range. Any call that enters the channel will finish it work before allowing any other call to the channel. Also it allows any call that is ready to seize the channel without any consideration.

The advantage of this method is that it allows the call to finish its work before any other call can be allowed to the channel. The disadvantage is that sometimes some calls might occupy the channel unnecessarily thereby denying others from entering.

1. START

2. DO WHILE SERVICE $=$ TRUE

3. SET $\mathrm{K}=1 / /$ INITIALISING THE TIMESLOT

4. DO WHILE NOT FREE AND $\mathrm{K}<=8 / /$ TESTING FOR FREE TIMESLOT

5. $\mathrm{K}=\mathrm{K}+1$

6. LOOP

7. IF TIMESLOT $=$ FREE THEN

8. LOAD THE CALL TO TIMESLOT (TK )

9. WHILE SERVICE TIME $<$ AIR_TIME

10. CONTINUE THE $\overline{\mathrm{C} A L L}$

11. WEND

12. ELSE

13. REJECT THE CALL

14. END IF

15. FETCH THE NEXT CALL

16. LOOP

\subsection{Dynamic Allocation Time Slicing with Signal Sensing}

This allows calls to occupy the channel with a maximum time interval. This will allow calls to occupy the channel with an attach time range. Unlike the block time-sharing, it will not preempt the calls automatically but a carrier sense will be passed at intervals to check if there is any call waiting. If there is any call waiting, then, the signal will preempt any call that had exhausted its maximum time allocation, otherwise, the call will be allowed to continue as long as the caller wishes to continue.

The advantages are:

- it does not allow the system to be occupied unnecessarily;

- it allows the subscriber to continue calling as long as they wish provided there is no call waiting.

The disadvantage is that it does not consider any call as important thereby essential calls will be pre-empted without finishing the call

1. START

2. SET THE MAX TIME

3. DO WHILE SERVICE $=$ TRUE

4. SET $\mathrm{K}=1 / /$ INITIALISING THE TIMESLOT

5. DO WHILE NOT FREE AND $\mathrm{K}<=8$

6. //TESTING FOR FREE TIMESLOT

7. $\mathrm{K}=\mathrm{K}+1$

8. LOOP

9. IF TIMESLOT $=$ FREE THEN

10. LOAD THE CALL TIMESLOT (TK )

11. WHILE SERVICE_TIME $<$ MAX_TIME AND NO CALL WAITING OR SERVICE TIME $<$ AIR CONTINUE THE CALL

\section{WEND \\ 13. ELSE \\ 14. REJECT THE CALL \\ 15. END IF \\ 16. FETCH THE NEXT CALL \\ 17. LOOP}

\subsection{Frequently Recent Call Allocation}

This method will give preference to some calls that were denied access but immediately redial within a specified time. What that means is that if there is any call that was among the one that came recently, the system will give a higher preference above the ones that are just appearing for the first time. This can be achieved by creating a small memory that will register the calls that were not given any service. So if any of these calls comes again, the system will first search the memory called cache if there is any of the call number has been registered in the cache before and if there is, the call will be served first. No call number should be allowed to stay more than a specified time interval like 1 minute in the cache so that some calls will not have undue privilege over the other. Also, higher preference will be given to numbers present in the cache. The memory should be created in the BSC as this is the gateway of every call to MSC. This memory will not affect the performance of BSC negatively since only a minimal number that will be here due to a purging mechanisms that will be removing the calls that have 
exceeded their I minute duration time in the memory.

The advantage of this method is that it will not allow some calls to be starved for too long period of time. It draws back is that it might lead to waste of service time because there might be a need to check every call against the already registered call in the memory (Konstain et al, 2003),.

1. START

2. DO WHILE SERVICE $=$ TRUE

3. SET $\mathrm{K}=1 / /$ INITIALISING THE TIMESLOT

4. DO WHILE NOT FREE AND $\mathrm{K}<=8 / /$ TESTING FOR FREE TIMESLOT

5. $\mathrm{K}=\mathrm{K}+1$

6. LOOP

7. IF TIMESLOT $=$ FREE THEN

8. LOAD THE CALL WITH THE HIGHEST NUMBER OF PRESENCE

9. WHILE SERVICE TIME $<$ AIR TIME

10. CONTINUE THE CALL

11. WEND

12. ELSE

13. REJECT THE CALL

14. REGISTER AT THE TEMPORARY MEMORY

15. END IF

16. FETCH THE NEXT CALL

17. LOOP

\subsection{Priority Allocation}

In this method every body should have a level of priority and this priority should have been integrated into the SIM card. So, anytime anybody buys a SIM card and activate it on the network, the priority level registered automatically. The priority level will be used throughout the period of subscription of the subscriber to the network. The level of priority will be determined by the nature of your service. This model will be able to take care of the executive essential duties officers like President, Governors, fire fighters, police and so on.

In this model, the principles of arithmetic operation preferences will be used where the highest priority will gain access to the channel before the lower priority. Also, people of the same priority will follow any other model for managing equal priority. So this model is meant especially for essential duties officers. In this model, time interrupt preemption will not apply; their access to the network will not be terminated until they terminate it themselves.

The advantage of this model is that it will allow the essential duties calls to complete their calls without any interrupt and thereby forestalls casualties that might occur if they were not given attention. The disadvantage of this method is that so many calls will be denied access during the time when the essential duties are on. Also, some calls that may be very important to some subscribers might be dropped and immediate reconnection may not be possible easily.

1. START

2. DO WHILE SERVICE $=$ TRUE

3. SET ESSENTIAL_CODES

\author{
4. SET $\mathrm{K}=1 / /$ INITIALISING THE TIMESLOT \\ 5. DO WHILE NOT FREE AND $\mathrm{K}<=8 / /$ TESTING FOR \\ FREE TIMESLOT \\ 6. $\mathrm{K}=\mathrm{K}+1$ \\ 7. LOOP \\ 8. IF TIMESLOT $<>$ FREE AND CALL $=$ ESSENTIAL \\ CALL THEN \\ 9. DROP CALL WITH LEAST PRIORITY \\ 10. LOAD THE ESSENTIAL CALL TO TIMESLOT \\ (TK ) \\ 11. WHILE SERVICE TIME $>0$ \\ 12. CONTINUE THE CALL \\ 13. WEND \\ 14. ELSE \\ 15. LOAD THE CALL TO TIMESLOT (TK ) \\ 16. WHILE SERVICE_TIME $>0$ \\ 17. CONTINUE THE CALL \\ 18. WEND \\ 19. END IF \\ 20. FETCH THE NEXT CALL \\ 21. LOOP
}

\section{Recommended Management Solution}

The recommended ways of managing congestion given here took into account the potential for capacity gains and subscribers satisfaction. The steps below are recommended as general order for introducing the different solutions in the network layer.

\subsection{Step Number One for Managing Gsm Network Congestion}

The first step is to determine the appropriate channel-loading model for the network. Make sure the number of channels to subscribers does not result into the operator's deficit. Then the below algorithm should be used to manage calls within the network. The recommended algorithm has a prioritization scheduled to maintain un-interrupted communication during emergency. It also provides a location for temporary memory to cater for incessant frequent callers within a specified period. It gives them a higher priority over a new entrant call. This algorithm should be implemented at every base station. The advantages of this algorithm are (Kuboye, 2006):

- It gave a priority to highly essential duties calls that needed immediate attention. This will thereby forestall any casualties that may occur if such attention is not given.

- It gave priority to the most denied calls to grab the channel when they appear within a specified time.

- It does not allow any call to occupy the channel more than necessary when they are calls waiting to grab the channel.

- It does not preempt the subscriber if there is no call waiting unlike the block-time that will preempt even if there is no call waiting 
- It allows dynamic allocation of channel when there is equal priority calls.

\section{RECOMMENDED ALGORITHMS}

1. START

2. DO WHILE SERVICE $=$ TRUE

3. SET ESSENTIAL_CODES

4. SET $K=1 / /$ INITIALISING THE TIMESLOT

5. DO WHILE NOT FREE AND $\mathrm{K}<=8 / /$ TESTING FOR

FREE TIMESLOT

6. $\mathrm{K}=\mathrm{K}+1$

7. LOOP

8. IF TIMESLOT $<>$ FREE AND CALL $=$ ESSENTIAL CALL THEN

9. DROP CALL WITH LEAST PRIORITY

10. LOAD THE ESSENTIAL CALL TO TIMESLOT (TK )
11. WHILE SERVICE TIME $>0$
12. CONTINUE THE CALL
13. WEND
14. ELSE
15. IF TIMESLOT $=$ FREE AND CALL $=$ ESSENTIAL CALL THEN

16. LOAD THE CALL TO TIMESLOT (TK )

17. WHILE SERVICE_TIME $>0$

18. CONTINUE THE $\overline{\mathrm{C} A L L}$

19. WEND

20. ELSE

21. IF TIMESLOT $=$ FREE THEN

22. LOAD THE CALL WITH THE HIGHEST NUMBER OF PRESENCE

23. WHILE SERVICE_TIME $<$ MAX_TIME AND NO WAIT SIGNAL OR SERVICE_TIME $<$ AIR_TIME

24. CONTINUE THE CALL

25. WEND

26. ELSE

27. REJECT THE CALL

28. REGISTER AT THE TEMPORARY MEMORY

29. END IF

30. END IF

31. END IF

32. FETCH THE NEXT CALL

33. LOOP

\subsection{Step Number Two for Managing GSM Network Congestion}

As the number of subscriber's increases, so traffic continues to grow, then the models below can be considered in conjunction with the above step. Note that the above algorithm should be implemented at every base station transceivers

\subsubsection{Cell Splitting}

So, as the number of subscribers increases in a particular cell site and the present channels could not carry them, the engineers should increase the number of channels until the maximum number of channels per base station is exhausted.
If this is exhausted, then the engineers should think of cell splitting. The engineers sometimes ought not to wait till the maximum number of channels are exhausted before doing the cell splitting because, too much of channels in a base station can cause interference.

\subsubsection{Multi-Band}

Operators who have access to spectrum in other frequency bands should start deploying equipment to use those frequencies. In the situation where 900 GSM type is installed, the operator should be thinking of 1800 GSM. This phenomenon is referred to as multi-band system. That means, the 1800 GSM can be installed, so that 1800 bands will automatically handle some of the calls thereby relieving the 900 GSM type.

\subsubsection{Micro-Cell}

In a situation where there is constant abnormal increase in the number of subscribers for some interval of days consistently like in an airport environment, stadium, churches camp ground like the RCCG camp, micro-cellular systems can be installed so as to take care of the sudden increase in the number of subscribers. The use of micro cells to cover hot-spots cell offload the macro cells, and help operators to avoid the cost of having to split cells. As traffic increases, the number of micro cells and indoor cells will also continue to grow (Kuboye, 2006). By adding more capacity to the micro cells, operators can achieve an extreme boost in capacity.

\section{Conclusions}

GSM is a digital system designed to meet the need of growing mobile subscribers, which the analog could not handled. It also provides a better quality services. As a result of these qualities, GSM has stood to be the most embraced and fastest growing technology in the field of communications. As a result of this embrace, many people wanted to have access to the network but not all are granted, this led to the congestion on the network. Congestion is now a threat to the maximum satisfaction of the subscribers and to the optimum gain of the GSM providers.

\section{REFERENCES}

[1] Angus, L., Introduction to Erlang B \& C, Tele Management Magazine, Canada, July- August, 2001

[2] Boulmalf M. and Akhtar S., Performance Evaluation of Operational GSM Air-Interface UM)", 2003

[3] Cushine, J. and Hutchison, D., Changing and Billing models for GSM Future Mobile Internet Service, 1997, Available online: http:// www.iec.com

[4] Candan And Salaman, Performance and Analysis of a Time-Threshold Based bandwidth Allocation Scheme for Data Calls in Cellular Networks, IEEE, 2006 
[5] Gupta and Sachan, Distributed Dynamic Channel allocation Algorithm for Cellular Mobile Network, Journal of Theoretical and Applied Information Technology, (2007)

[6] Hartel, Levine and Livingstone, "GSM Superphones", McGraw-Hill, (1999)

[7] Salim H. and Bli H., Performance Enhancement of GSM Cellular Phone Network using Dynamic Frequency Hopping, Journal of Eng.\&Tech., Dept.of Electromechanicl.univ.of tech., Vol.26.No.3., 2008

[8] Kleinrock, L., Queuing systems Theory, volume I, John Wiley, New York, 1975

[9] Konstain et al (2003) "Radio Resource Management schemes for combines GSM /GPRS Mobile by stems", Wireless Communication Mobile Computing Journal; 357-384
[10] Kuboye B. M. "Development of a Framework for Managing of Congestion in GSM in Nigeria", Masters Thesis, 2006

[11] Kuboye, B.M. and B.K. Alese, "The Pathway of GSM to 3G Systems in Nigeria, Pacific Journal of Science and Technology. 10(2):388-397, 2009, Available online: http://www.akamaiuniversity.us/PJST.htm

[12] Kuboye B.M., Optimization models for minimizing congestion in Global System for Mobile Communications (GSM) in Nigeria" Journal of Media and Communication studies Vol. 2(5), pp. 122-126, May 2010, Available online http://www.academicjournals.org/jmes ISSN 2141 - 2545

[13] Mehrotra, A. (1997), "GSM System Engineering”, Artech home, Inc.1997

[14] Ryscard S. "Introduction to Congestion Theory in Telephone Systems" Elserier Science Publishers B.V.,1986 